IJPS है दे टु م. No Se.0.2. $r$ -

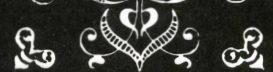

International Journal of Philosophical Studies

Volume 2 • Number 1 • March 1994 


\section{International Journal of Philosophical Studies}

All manuscripts should be sent to the Editor:

\author{
Professor Dermot Moran \\ Department of Philosophy \\ University College Dublin \\ Dublin 4 \\ Ireland
}

Review copies to Dr Maria Baghramian at the above address.

Subscriptions rates for Vol. 2, 1994 (two issues)

$\begin{array}{lll}\text { UK/EC } & \text { Institutional } & £ 48 \\ & \text { Personal } & £ 27.50 \\ \text { North America } & \text { Institutional } & \$ 85 \\ & \text { Personal } & \$ 45 \\ \text { Rest of World } & \text { Institutional } & £ 55 \\ & \text { Personal } & £ 30\end{array}$

bscription orders should be sent to the publishers, Routledge Journals, Cheriton House, North Way, Andover, Hants SP10 5BE, UK.

\section{Published by Routledge \\ 11 New Fetter Lane \\ London EC4P 4EE \\ UK}

(C) Routledge, 1994

ISSN 0967-2559

The Editor gratefully acknowledges the support of the National University of Ireland

Printed in Great Britain by Bell and Bain Ltd, Glasgow

\section{Phainomena in Aristotle's Methodology}

\author{
John J. Cleary
}

\section{Introduction}

The task of elucidating the function of phainomena in Aristotle's method (or methods) ${ }^{1}$ of inquiry raises some philosophical and historical problems. Historically, it is unclear how the astronomical method of 'saving the phenomena' developed within the context of Plato's Academy and its scientific and philosophical projects. On the one hand, it is reported that he prescribed such a method to contemporary astronomers for the reform of their science, yet on the other hand it is hard to believe that an amateur could lead professionals by the nose. Due to the importance for ancient astronomy of the contributions made by Eudoxus and Callippus, one must assess how much Aristotle was influenced by their methodological approach in his own scientific inquiries. Given his departmentalization of the sciences, however, we cannot assume that he applied the method of a mathematical science like astronomy in a straightforward way to other theoretical sciences like philosophy or to practical sciences like politics. Thus, in view of the radical differences between these sciences both in subject-matter and in precision, it has been doubted whether they can share a common methodology.

In view of this doubt, my paper will concentrate on exploring how phainomena function in Aristotle's theoretical and practical sciences. Against Terence Irwin's attempt to distinguish sharply between empirical and dialectical inquiries, I will argue that for Aristotle different kinds of science share a common procedure in which phainomena perform two major functions. First, they serve as the starting-point of every search for first principles, especially when the science in question is demonstrative, since Aristotle insists that these principles themselves cannot be demonstrated. But the second function of phainomena is to provide a test for the adequacy of the first principle that emerges from the initial stage of inquiry. In fact, his method of first reviewing the phainomena is based on the assumption that some truth is hidden in them, whether they be sensory appearances or

International Journal of Philosophical Studies Vol. 2(1), 61-97 
common opinions. Aristotle's chief methodological problem is to specify a way of finding the appropriate first principles among a jumble of sensory appearances and common opinions which one can easily collect on any subject. In order to show that these principles are suitable, he must specify how one can give some justification for what are indemonstrable 'firsts'. Once the first principles have been secured, then Aristotle's syllogism is the appropriate tool for drawing out the conclusions in a way that preserves whatever truth or plausibility is contained in the premises. I shall not concern myself here with this standard way 'from the principles', except to note that it is often absent from Aristotle's inquiries, possibly because it presents less difficulty than the way 'to the principles'.

I will try to show how Aristotle justifies first principles in a way that parallels the so-called method of 'saving the phenomena'. It involves gathering the phainomena in a comprehensive way such that all or most of the logical possibilities are covered, and such that they conflict with each other. As a result the inquiry generates puzzles which are resolved by a thorough scrutiny of the phainomena in order to discover a tentative first principle that will prove its mettle by 'saving the phenomena'. When all of this has been done, according to Aristotle, it is sufficient as a 'proof' for a first principle which now becomes the starting-point for theoretical demonstration or practical action. ${ }^{2}$ In this way reputable opinions ( $\varepsilon \vee \delta \circ \xi \alpha$ ) and authoritative appearances play a central role as tests for first principles in a method of inquiry that is common to his theoretical and practical sciences. Such reliance on phainomena is typical of Aristotle's philosophical thinking, as distinct from Parmenides and Plato who insist on a sharp contrast between appearance and reality.

\section{Historical Context}

According to Simplicius (in De Cael. 488.18-24, 493), it was part of the Platonic tradition in astronomy to take its central task as that of 'saving the phenomena'. Possibly motivated by the assumption that the motion of divine bodies must be perfectly circular and uniform, Plato reputedly set astronomers the task of finding the number and arrangement of such motions that must be posited to explain the apparently irregular motion of the planets. This seems to have been the problem that exercised Eudoxus when he put forward his theory of homocentric spheres, and Callippus when he modified his theory to make it conform better with certain important phenomena. In these cases the phenomena were the position, shape, and motion of the most visible heavenly bodies, especially those associated with the signs of the zodiac. But the most difficult problem for astronomers was that of the apparent retrogradation of the planets to which Plato also refers in passing at Tim. 40c.
It was to the latter problem, in particular, that Eudoxus' theory o concentric spheres represented such a brilliant and original solution. ${ }^{3}$ Here the phenomena are treated as significant and, hence, as being in need of 'saving' through the hypothetical method of positing the real motions, which are assumed to be uniform and circular. The showpiece of this whole
ingenious theory was the manner in which retrograde motion of the planets (in the it could reproduce the apparent through the combined motions of differentedized form of a hippopede) speeds and angles of rotation; (1952). Even if the Eudoxean model Schiaparelli (1877) and Neugebauer it gave a plausible qualitative and geometrical determined quantitatively, surrounding the retrograde motions and solution to the problems such it was accepted as a paradigm by duced additional spheres for a better fit bus and Aristotle, who introphenomena. method of 'saving the phe must locate the within philosophical contexts should be claim that subsequent adaptations ilarly, I think that the meaning of least partially definitive for its of $\phi \alpha \iota v o$ ó $\mu v \alpha$ within this specific context is at cal inquiries. Thus we must take note use in other scientific and philosophientitled Phainomena which take note of the fact that Eudoxus wrote a book together with fairly exact information a detailed description of the heavens, together. ${ }^{5}$ For instance, he reports the feet of Cepheus, making an that 'beneath the tail of the Little Bear lie (Hipparchus I, 2.11). Sul the tip of the geometrical idealization a mixture of empirical observation and of nomena. ${ }^{6}$ Similar Meteorology, where he refers to also be found in Aristotle's De Caelo and Cael. 292a3, Meteor. 345a1, to what 'we have seen' in the heavens (De фaıvó $\mu \varepsilon v \alpha$, it is important to note. Yet, given his wider use of the term reliability between our perception that he was aware of the difference in earth (De Part. An. I. 5, 644b24 ff) In heavenly bodies and of things on this parallel between the method $24 \mathrm{ff}$ ). In spite of this, however, he insists on the sciences $(A P r .46 a 19-21$ and of astronomy and that of other more physical claims here is that this parallel De Part. An. 639b7-11). One of my major method of scientific inquiry.

\section{Aristotle and the Astronomers}

In assessing the influence of contemporary astronomy on Aristotle's method of inquiry, one should begin with Metaphysics Lambda 8 because not only modest contribution to theward practising astronomers but it also includes a 
own appropriation of the astronomical method of inquiry, while elucidating the reasons for Aristotle's unusual deference toward this most physical of the mathematical sciences, as he describes it elsewhere (Phy. II.2, 193b25-26).

It is quite significant that the astronomical discussion in Lambda 8 occurs within the context of a general metaphysical inquiry about supersensible substance, whose existence and nature have been established in previous chapters. Therefore, the guiding question for this chapter is whether there is one or many of such substances. The argument for the existence of at least one unmoved mover was based on the apparent fact that the whole universe has one simple (diurnal) and eternal motion. But, since there are other simple locomotions (e.g. the planets move in the opposite direction along the ecliptic) which are eternal, then it is reasonable to assume that there are other unmoved movers, which are ultimately responsible for these motions. So Aristotle argues that there will be just as many such substances as there are simple and eternal motions, and that they will be ordered in the same way; cf. 1073a36-39. In support of his metaphysical argumentation, he calls upon the science of astronomy:

Now as regards the number of locomotions, this should be the concern of the mathematical science which is closest to philosophy, and this is astronomy; for it is this science which is concerned with the investigation of sensible but eternal substances, while the others, such as arithmetic and geometry, are not concerned with any substances.

Here Aristotle differentiates between astronomy and other mathematical sciences, such as arithmetic and geometry, in terms of the ontological status of their respective objects of inquiry, rather than in terms of different methods for mixed and for abstract sciences. Since he differentiates sciences in terms of characteristic objects, their ontological status may have implications for the sort of arguments and the kind of phenomena proper to each science. Thus, even though astronomy is held to be subordinate to geometry (cf. Posterior Analytics I. 27), the ontological status of its objects makes it superior, since the heavenly bodies are both sensible and eternal substances. ${ }^{8}$ This is what makes astronomy the mathematical science closest to philosophy, by contrast with those which study merely 'abstract' objects While this contrast has many interesting implications, I will focus on what it means for the method of astronomy, by comparison with that of arithmetic or geometry.

With respect to this question, the most important point about astronomy seems to be that it studies sensible substances, whereas arithmetic and geometry study abstract intelligible objects. This is important because, although the astronomer uses hypothetical constructions just like the geometer, he cannot ignore the sensible phenomena in assessing the truth of his hypotheses. Furthermore, while an inexperienced boy can learn geometry, he cannot learn astronomy without the right sort of experience, which involves among other things the observation of heavenly bodies. It is precisely on these points that Aristotle parts company with Plato (in Republic VII) when the latter urges astronomers to reform their science by treating things in the heavens just as a geometer treats diagrams: i.e. as useful but as dispensable. This parting of the ways is nicely underlined in the above passage where Aristotle looks to astronomers to settle the empirical ${ }^{9}$ question of just how many simple and eternal motions are necessary to save the phenomena. Although Plato's hypothetical method is not abandoned, the phenomena function as the last court of appeal in deciding on the truth of astronomical hypotheses. Aristotle is also willing to accept tentative answers:

But as to the number of these, we may for the present give an indication by quoting what some mathematicians are saying, so that there may be in our thought a belief in some definite number; as for the rest, we should partly investigate ourselves and partly inquire from those who investigate the subject, and if those who are investigating this subject have opinions contrary to those just stated, we should respect both views but accept the more accurate. ${ }^{10}$

Here we find some valuable hints as to how Aristotle appropriated the typical method of astronomy, especially given the privileged relationship of that science to his own metaphysical inquiry. In order to settle the question of how many supersensible substances exist, for instance, one must determine through astronomy just how many simple and eternal motions there are in the universe. Although Aristotle is not satisfied that this has been conclusively decided, he reports the views of both Eudoxus and Callippus in order to show how the systematic correlation will work. While he engages in some astronomical speculation himself, he is prepared to accept better informed opinions from experts in the science. But the general methodological rule governing the whole inquiry is that, while contrary opinions are to be

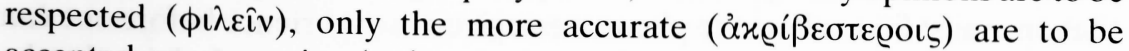
accepted as persuasive ( $\pi \varepsilon i \theta \varepsilon \sigma \theta \alpha \mathrm{l})$; cf. 1073b15-17. Although 'saving the phenomena' refers especially to the sensible heavens, I think that this rule can be seen to guide Aristotle's own philosophical and ethical method of inquiry in which the most reputable opinions are gathered, tested and preserved. In this regard, one should note that his conclusions are described

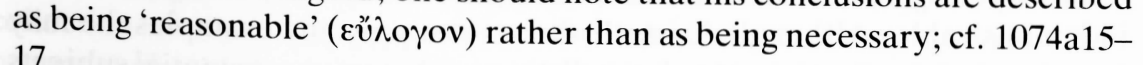
17.

The importance of astronomy for Aristotle's conception of scientific method is shown by a passage in Prior Analytics I. 30, where that science features prominently as a paradigm. The context is provided by some general methodological remarks which are clearly intended to apply in all cases, 
whether in philosophy or in any craft ( $\tau \dot{\varepsilon} \chi \vee \eta)$ or in any theoretical inquiry $\left(\mu \alpha \theta \eta^{\prime} \mu \alpha\right)$. The whole chapter serves as a kind of summary of Aristotle's previous discussion of how syllogisms are constituted from premises which are themselves constructed from terms connected in certain ways. With reference to this discussion, he now $(46 \mathrm{a} 8-10)$ makes a general distinction between demonstrative syllogisms that begin from true premises, and dialectical syllogisms that start from plausible premises. ${ }^{11}$ But logic by its very nature is general, whereas the peculiar ( $\left({ }^{\prime} \delta \iota \alpha \iota\right)$ principles of each science must be sought in experience:

Consequently it is the business of experience to give the principles which belong to each subject. I mean for example that astronomical experience supplies the principles of astronomical science; for once the phenomena were adequately apprehended, the demonstrations of astronomy were discovered. Similarly with any other art or science. Consequently, if the attributes of the thing are apprehended, our business will then be to exhibit readily the demonstrations. For if none of the true attributes of things had been omitted in the survey, we should be able to discover the proof and demonstrate everything which admitted of proof, and to make that clear, whose nature does not admit of proof. ${ }^{12}$

Although this passage does not specify how astronomical hypotheses are to be justified in relation to the phenomena, yet it is significant that astronomy is cited as a model for all inquiry which uses the collection of phenomena as a way to first principles. In fact, as Heath (1949: 25) notes, there is historical evidence that Aristotle is reporting an established distinction among astronomers between observational and theoretical astronomy. Eudoxus, Aratus, Euclid and Geminus are all credited with books of observations, bearing the conventional title Phainomena, which are different from works of theoreti-

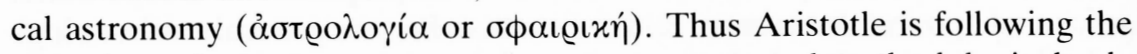
precedent of astronomy when he accepts as a general methodological rule that one must first collect the phenomena given in experience before one can find the appropriate first principles for any science or art. I claim that he himself follows this rule throughout his empirical and dialectical inquiries.

The anticipated outcome of a comprehensive collection of astronomical phenomena, according to the above passage, is that one will find the proofs for everything that is demonstrable and also show what is by its nature indemonstrable. Although Aristotle does not supply any examples, he may have in mind the Posterior Analytics distinction between substantial subjects like the sun or the moon, which are simply assumed to exist, and their attributes which are proved to belong necessarily to them by means of a middle term. This distinction is consistent with what he says about the collection of phenomena, since these will be primarily reports about the attributes of heavenly bodies which are assumed to exist on the basis of perception. In the case of a lunar eclipse, for instance, a set of careful observations of the shape of the advancing shadow may lead one to discover the hidden cause, i.e. the interposition of the earth between the moon and its source of light. This explanation can then be used as a middle term in a scientific demonstration about lunar eclipses, which presupposes the existence of sun, moon and earth. Indeed, without such preliminary assumptions the inquiry could not even begin because there would be no focus for the collection of phenomena. In Aristotelian terms, the inquiry about 'the

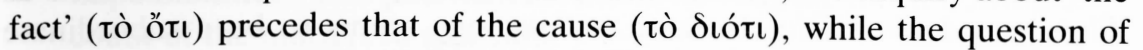
existence is prior to that of essence; cf. Post. An. II.1-2.

Let us now look at a parallel passage in De Partibus Animalium I, which is of interest not only because it bears on this point but also because it introduces an inquiry in biology. It contains the second of a series of methodological questions posed in Aristotle's introduction:

Should the natural philosopher, like the mathematicians when they demonstrate astronomy, first survey the appearances in regard to the animals and their parts in each case, and only then go on to state the because-of-what (i.e. the causes), or should he proceed in some other way ${ }^{14}$

Finding an answer to this question is a task for the generally educated person

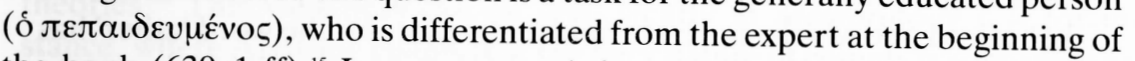
the book (639a1 ff). ${ }^{15}$ In any event, Aristotle's own practice as an expert inquirer about nature shows that he accepts an affirmative answer to the above methodological question. For instance, he insists that one must first grasp the appearances ( $\tau \grave{\alpha} \phi \alpha \iota v o ́ \mu \varepsilon v \alpha$ ) about each genus and then proceed to discuss their causes (640a14-15). From the broader context and from the examples supplied, we may conjecture that Aristotle has in mind such attributes as sleep and breathing which belong to many genera of animals in different but analogous ways. This shows that, in answer to the first methodological question, he takes the view that one must first survey the common generic attributes before getting down to those which are peculiar to the species (639b3 ff).$^{16}$ In some cases, the distinction holds within the same science, whereas in other cases it involves two different sciences. For example, acoustical harmonics yields knowledge of the fact only, while the cause is supplied by arithmetic. Similarly, nautical astronomy consists of a collection of observations, whereas mathematical astronomy provides the proper explanations. In his biological inquiries, Aristotle seems to follow the Historia Animalium bers when he makes a general collection of data in the Historia Animalium before going on to search for causes in particular treatises like De Partibus Animalium and De Generatione Animalium. Likewise, in the practical sphere, his collection of constitutions seems to 
have been intended as a preliminary to his inquiry about causes in the Politics. In general, I think that this division has better support in Aristotle's own practice than Irwin's proposed division between empirical and dialectical inquiry.

In support of my claim, let me briefly examine Aristotle's method of inquiry in Meteorology and De Caelo, both of which illustrate how a scientist inquires into the things 'aloft' in the heavens. At the beginning of the Meteorology, Aristotle recapitulates on the principles of the heavenly and sublunary bodies, which he takes over from previous treatises such as Physics and De Caelo. In fact, meteorology seems to be a subordinate science concerned with the phenomena that belong to the region between the immutable heavens and the earth itself. So Aristotle makes no attempt in the Meteorology to give demonstrative syllogisms, but instead follows the hypothetical method that astronomers use to save the phenomena.

In I. 3, for example, Aristotle sets out to explain comets and other phenomena which he treats as belonging to the same region of the universe and as having the same causes. But first he recalls some fundamental assumptions about the nature and motion of the four sublunary elements, and about a fifth element which was posited in De Caelo I as the material of the heavenly bodies. In support of this latter principle, he cites the general consensus among previous thinkers:

This is an opinion we are not alone in holding: it appears to be an old belief and one which men have held in the past, for the word 'ether' has long been used to denote that element. Anaxagoras, it is true seems to me to think that the word means the same as fire. For he thought that the upper regions were full of fire, and that men referred to those regions when they spoke of ether. In the latter point he was right; for men seem to have assumed that a body that was eternally in motion was also divine in nature; and, as such a body was different from any of the terrestrial elements, they determined to call it 'ether'. ${ }^{17}$

Two important points about Aristotle's canons of evidence are illustrated in this passage. By contrast with Plato, he treats universal consensus as one indicator of truth and so he seeks support for his own principles in the views of predecessors. Secondly, Aristotle appeals to linguistic evidence in support of what we would regard as an empirical claim about the material of the heavenly bodies. But such an appeal may seem less strange if we view language as a repository for the experience of previous generations.

If one assumes that the Meteorology is an empirical treatise, however, it is rather surprising that Aristotle should proceed in a dialectical manner as follows. First he gathers the common opinions about a topic and reviews the difficulties connected with them; then he introduces his own hypothesis to resolve the difficulties and, thereby, saves the phenomena; cf. $340 \mathrm{~b} 3 \mathrm{ff}$. In
I. 6, for example, he sets out to explain the nature of comets by giving a preliminary outline of the views of his predecessors on the subject. Next, he reviews the major difficulties and objections which tell against all or some of these theories about comets and which show them to be false. Subsequently, in $\mathrm{I}$. 7 , he justifies his own explanation by the following criterion:

We consider a satisfactory explanation of phenomena inaccessible to observation to have been given when our account of them is free from impossibilities. The phenomena available suggest the following account of the matters in question. ${ }^{18}$

Even though this criterion is applied specifically here to heavenly phenomena which are difficult to perceive by virtue of distance, Aristotle suggests that it can be applied generally to other phenomena that are not directly accessible to sensory observation. If that is the case then his criterion of adequate explanation is one of logical consistency between the available phenomena and the explanatory theory. But such a criterion is also applicable to other inquiries besides astronomy and meteorology; and hence this passage indirectly supports my thesis about the analogical unity of Aristotle's methodology. ${ }^{19}$

In fact, his general method of inquiry makes him too quick to accept apparent correlations between events as confirmations of his explanatory theories. ${ }^{20}$ This weakness can be seen clearly in Meteorology I.7, for instance, where Aristotle claims that the fiery nature of comets is confirmed by the coincidence of wind and drought with their appearance. ${ }^{21}$ According to his theory, comets result from dry exhalations that have risen up towards the boundary of the sublunary realm and that have been ignited by friction against the nearest sphere of the heavenly bodies. So when comets are plentiful, the air through which the exhalations rise is necessarily drier and, as a result, there is drought. When they are fewer, according to Aristotle, the effect is not drought but winds that are excessive either in duration or strength. In support of his explanation, he cites the reported fact that a great wind coincided with the fall of a stone at Aegospotami, and so he thinks the wind must have been responsible for carrying it up during the night. ${ }^{22}$ Coincidentally, he mentions that a comet had appeared in the west at the same time and so he takes his theory to be confirmed $(344 \mathrm{~b} 30 \mathrm{ff})$. In view of the fact that Anaxagoras (DK 59A 11,12) had cited this event in support of his claim that heavenly bodies like the sun are fiery stones, Aristotle seems to be ignoring other possible explanations of these events. Indeed this is an example of the way in which general theoretical assumptions guide his interpretation of sensible phenomena. In any event, my brief look at the Meteorology shows that Aristotle makes no sharp distinction between empirical facts and common opinions about the attributes of things 'aloft'. ${ }^{23}$ 
Let us now turn to De Caelo I, where Aristotle discusses general questions about the universe such as whether it is one or many, eternal or generated. Since I am interested chiefly in methodological issues, however, I will not consider his answers to these questions except where they illustrate a point of method. In I. 3, for instance, he canvasses some logical arguments in support of the view that the primary body (ether) is ungenerated and indestructible. Having rehearsed these, Aristotle goes on to say:

The reasons why the primary body is eternal and not subject to increase or diminution, but unageing and unalterable and unmodified, will be clear from what has been said to any one who believes in our assumptions. Our theory seems to confirm the phenomena and to be confirmed by them..$^{24}$

The crucial sentence here is the last, which sums up his conception of the dual relationship between theory and phenomena. On the one hand, if one accepts the principles that have been posited then it is possible to explain the phenomena as consequences. This is what Aristotle has been doing in the previous section and that is why he mentions trust in the hypotheses (tois ú obvious. On the other hand, the same conclusions may also be accepted on the grounds that the hypotheses are confirmed by the phenomena. Thus, Aristotle says, it seems that the argument bears witness to the phenomena and that the phenomena, in turn, bear witness to the argument. ${ }^{25}$ Since the Greek construction gives only one verb ( $\mu \alpha \varrho \tau v \varrho \varepsilon i v)$ to cover both aspects of this logical relationship, we may assume that he saw them as being symmetrical. In other words, he regards the deduction of phenomena from first principles and the confirmation of such principles by means of the phenomena as inversely related procedures, just like analysis and synthesis in mathematics. This suggests that the hypothetico-deductive form of explanation is being extrapolated from astronomical inquiry into more philosophical modes of reflection. ${ }^{26}$

We should also notice the sort of phenomena to which Aristotle subsequently appeals as bearing witness to the truth of hypothetical explanations. In support of his claim about the divinity and eternity of the primary body, he cites an almost universal opinion among Greeks and barbarians that divinity has the highest place in the universe, namely, in the heavenly bodies (De Cael. 270b6-10). Here the criterion of general consensus is invoked by Aristotle to show that his claims about the unchangeable aether are well $(x \alpha \lambda \hat{\omega} \varsigma)$ founded. But he also cites the evidence of the senses as being

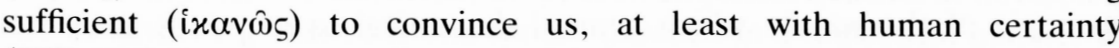
(270b13ff). ${ }^{27}$ Given the distance of heavenly bodies from us, it is not surprising that Aristotle admits sense perception to be fallible in this case, though he insists that it provides sufficient evidence for human confidence to

\section{PHAINOMENA IN ARISTOTLE'S METHODOLOGY}

be placed in it. Finally, as another kind of supporting evidence, he appeals to the tradition of calling the primary body aither, which he analyses etymologically as being derived from the fact that it 'runs always' ( $\alpha \varepsilon \grave{\imath} \theta \varepsilon i ̂ v-$ $270 \mathrm{~b} 23-4)$. Whether or not this etymology ${ }^{28}$ is correct, it shows that language is one of the relevant phenomena for Aristotle because he sees it as a repository of truth that can be drawn on by each generation. In this context, he repeats the belief that the same ideas recur to mankind again and again, presumably because they are eternally true $(270 b 20-1)$. So, along with the records of astronomical observations, linguistic usage and reports of previous opinions are treated as legitimate phenomena in cosmology.

At De Caelo II.5 Aristotle is engaged in the task of searching for an ultimate or a penultimate cause for heavenly bodies moving in one direction rather than another. Within this context he considers the potential objection that seeking such a proof shows a lack of paideia, and he replies that this depends on whether one is seeking merely human conviction or rather something unassailable. Personally, he would be grateful for more precise proofs but he is prepared to settle for what is plausible ( the absence of clear perceptual evidence about such ultimate causes, he falls back on two cosmological principles; i.e. that nature always yields the best result, and that forward motion is superior to backward motion. These principles supply the explanation which enables him to solve the puzzle $(\dot{\eta}$

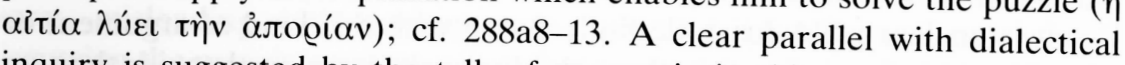
inquiry is suggested by the talk of an aporia in this context, and by its resolution through an appeal to plausible cosmological hypotheses. ${ }^{29}$

Finally, let us briefly consider a passage from De Caelo II. 13 where Aristotle criticizes the astronomical method of the so-called Pythagoreans. The context for his critique is provided by an inquiry into the location, motion, and shape of the earth (293a15 ff.). As usual, he begins with a review of divergent opinions about the position of the earth. Most thinkers who hold the universe to be finite think that the earth lies at the centre but the Italian philosophers known as Pythagoreans take the contrary view:

At the centre, they say, is fire, and the earth is one of the stars, creating night and day by its circular motion about the centre. They further construct another earth in opposition to ours to which they give the name counter-earth. In all this they are not seeking for theories and causes to account for the phenomena, but rather forcing the phenomena and trying to accommodate them to certain theories and
opinions of their own. ${ }^{30}$

From a methodological perspective, the importance of this passage is that it contains a clear contrast between what Aristotle considers to be right and wrong ways of relating theory and phenomena in astronomical explanations.
The right way is to seek explanatory accounts that conform with the 
These thinkers seem to push their inquiries some way into the problem, but not so far as they might. It is what we are all inclined to do, to direct our inquiry not to the matter itself, but to the views of our opponents; for even when inquiring on one's own one pushes the inquiry only to the point at which one can no longer offer any opposition. Hence a good inquirer will be one who is ready in bringing forward the objections proper to the genus, and that he will be when he has gained an understanding of all the differences..$^{33}$

This passage throws some light on Aristotle's understanding of the difference between a peirastic argument and a more scientific inquiry. A peirastic argument does not dig deeply enough into a problem because it has a tendency to stop when either the opponent or oneself has no further objections to offer ${ }^{3+} \mathrm{By}$ contrast, a scientific inquiry tries to bring forward al possible opinions on a question together with all the appropriate objections, so that one has a comprehensive treatment of the subject-matter covering all its differentiae. In Aristotle's own method of inquiry there are several ways by which he seeks comprehensiveness, i.e. by setting out all the logical possibilities and by gathering all the opinions on a particular topic or all the appearances related to a specific subject-matter. Having made these kinds of exhaustive surveys, he then systematically tests each possibility in his search for a first principle that will save the phenomena. This is different from the sort of ad hominem testing that was characteristic of Socratic dialectic, since the elenchus was complete when the opinions of one person were refuted Here Aristotle may also have in mind the comprehensive collection of phenomena which always preceded the search for causes in astronomy. It was typical of such inquiries that they gathered all the differences belonging to a particular genus as subject-matter of science; cf. De Part An. I.1, 639b414.

Another important feature of these scientific inquiries is highlighted by the care with which Aristotle distinguishes between different subject genera and their appropriate first principles. This may be seen as his reaction against the excessively 'common' method of Platonic dialectic, which tried to derive all scientific knowledge from a few general principles. Aristotle thinks that this leads the Platonists, just like the Pythagoreans, to do violence to the phenomena. We gather this much from De Caelo III.7 where he considers the question of how the elements are generated. He begins the inquiry in his typical fashion by outlining the possibilities through a review of opinions. One of these opinions clearly corresponds to the passage in the Timaeus which explains the generation of the so-called elements in terms of the analysis of solids into plane surfaces, and which denies that all of the elements can be transformed into each other. But Aristotle thinks that this is

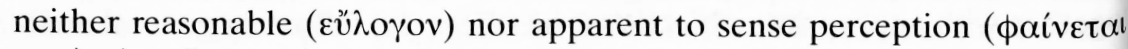

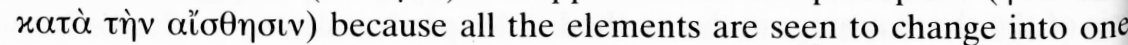

another (306a4-5). ${ }^{35}$ Thus, even though the Platonists speak abo

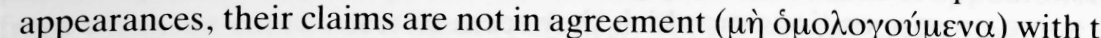
appearances. His analysis of why they fail to save the phenomena is that the have a mistaken conception of primary principles, as evidenced by the efforts to make everything conform to some predetermined beliefs. ${ }^{36}$

I think it is clear that Aristotle indicts them for using mathematic principles in an a priori fashion to settle a question in physics, when he goe on to say:

It seems that perceptible things require perceptible principles, eternal things eternal principles, corruptible things corruptible principles; and, in general, every subject matter principles homogeneous with itself. But they, owing to their love for their principles, fall into the attitude of men who undertake the defence of a position in argument. In the confidence that the principles are true they are ready to accept any consequence of their application. As though some principles did not require to be judged from their results, and particularly from their final issue! And that issue, which in the case of productive knowledge is the product, in the knowledge of nature is the phenomena always and properly given by perception. ${ }^{37}$

In this passage he enunciates a basic maxim of his departmentalization of the sciences, i.e. that every subject-matter ought to have its own peculiar principles. Presumably he includes the distinction between physics and mathematics when he says that perceptible things demand perceptible principles, whereas eternal things call for eternal principles; cf. Met. 1026a13-16, 1061b27-33, 1064a31-33, Phy. 198a29-31. ${ }^{38}$ For instance, the basic assumptions of a productive science should be criticized in the light of its goal, which is a product of some sort. In the same way, Aristotle says, the goal of natural science is to explain what appears authoritatively in accord-

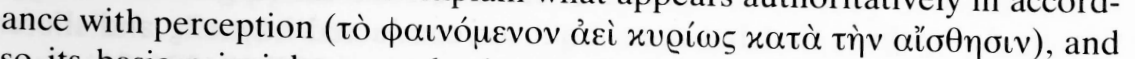
so its basic principles must be judged by how well they save these phenomena. Thus, in contrast to the Platonists, he holds that the physicist cannot simply accept the consequences of a mathematical theory if these conflict with the most reliable sensible phenomena. Unfortunately, he does not here give us any criterion for judging the most authoritative ( $x$ víi $(\omega 5)$ sensible phenomena, though one might guess that it is similar to the criterion of general consent for the most trustworthy endoxa. ${ }^{34}$

In his recent work, Terence Irwin $(1987,1988)$ has cast doubt on Owen's (1961) view that universally accepted common beliefs function as firm data in a dialectical inquiry in the same way that authoritative perceptual appearances function in empirical inquiry. Irwin's doubt rests on his claim about radical differences between these two types of inquiry which, if it were proved, would undermine my thesis about the analoginquiry which, if it were 
method. Therefore, I will briefly examine his major claims, while questioning some presuppositions on which they seem to rest.

In opposition to Nussbaum $(1982,1986)$, Irwin emphasizes Owen's contrast between Aristotle's descriptions of empirical inquiry and of inquiry proceeding from common beliefs. As an illustration of the first, he cites the passage that I have quoted from the Prior Analytics where astronomy is used as a paradigm for empirical inquiry. He takes this to show that one type of appearance belongs to empirical inquiry and that an accumulation of such appearances provides the basis for empirical science, since it leads to the discovery of generalizations which are then used in demonstrations. By contrast, he argues, it is another type of appearance that Aristotle has in mind in Nicomachean Ethics VII. 1 when he talks about 'setting out the

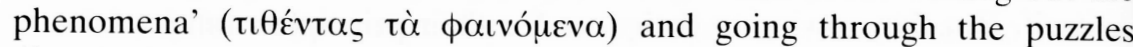
( $\delta\llcorner\alpha \pi \circ \varrho \eta \sigma \nu \tau \alpha \varsigma)$ because he says that, if the difficulties are resolved and the reputable beliefs ( $\tau \dot{\alpha} \varepsilon^{\prime} v \delta o \xi \alpha$ ) are left standing, this is an adequate proof

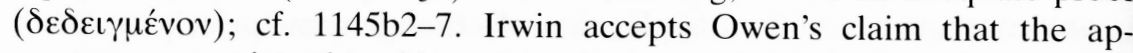
pearances mentioned in this passage just are common beliefs, rather than the results of empirical inquiry and observation; so that there are two types of phenomena that belong to quite different kinds of argument and inquiry. But Irwin refuses to go along with Owen's attempt to find something common in Aristotle's procedure within the different types of inquiry to be found, for example, in the Physics and the Historia Animalium.

It should be clear by now that I side with Owen and Nussbaum in emphasizing the common structure of Aristotle's methodological procedures which I hold to be derived from the method of astronomy. Indeed there is some historical precedent for this in Plato who used a similar hypothetical method as a model for his own dialectical procedure. If Irwin is to be consistent, therefore, he must claim that Aristotle refused to accept this precedent and that he distinguished explicitly between empirical and dialectical inquiries. But the most plausible candidate for such a general distinction in Aristotle is that between inquiries conducted $\lambda$ o $\gamma(x \omega \varsigma 5$ and those

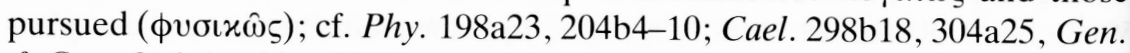
\& Corr. 316a11, Met. 1066b26, 1069a28, 1091a18, EN 1147a24. This Aristotelian distinction cuts across the boundaries of subject-matter, yet it does not divide things in the way that Irwin requires. I will return to this division after reviewing the major points of Irwin's argument.

One of Irwin's central claims is that Aristotle recognizes, at least in practice if not explicitly, a sharp distinction between perceptual appearances and common beliefs, along with a corresponding distinction between types of inquiry associated with them. He insists (1987: 116; 1988: 30-1) that there is no reason to suppose that all common beliefs, or even widely accepted common beliefs, count as perceptual appearances. ${ }^{+0}$ Conversely, he thinks that not all perceptual appearances have to be common beliefs, as Aristotle makes clear when he claims that the result of accumulating perceptions as preserved by memory is experience, which itself is the source of appearances from which we construct a theory; cf. Met. 980b28-981a1, APr. 46a17-25, Meteor. 353b17-18. Irwin seems justified in claiming that for Aristotle experience is a precondition for offering a plausible theory, though not in claiming that experience is derived exclusively from perceptual appearances. While Aristotle does insist that one must have the right kind of experience before one can find the appropriate principles in any subjectmatter, perceptual appearances can hardly serve as the basis for ethics, for instance, where the necessity of experience is emphasized especially by way of contrast with mathematics. ${ }^{41}$ If we have too little experience then, while we may be able to answer all the objections raised by ourselves or others, we will not have pursued the puzzles far enough to see all the objections that arise from the subject itself; cf. De Cael. 294b6-13. Thus I think that Aristotle's notion of the right sort of experience is relative to the subjectmatter involved, rather than to any general distinction between perceptual appearances and common beliefs.

By contrast, Irwin (1987: 117) thinks that the only route to experience is through historia, which is the kind of empirical inquiry that grounds Aristotle's biological works. Having assumed that this sort of inquiry is the only source of experience, Irwin goes on to distinguish different types of appearance on the rather shaky grounds that Aristotle never suggests familiarity with common beliefs to be sufficient for the type of experience relevant for historia. He notes that this term is never applied to a survey of dialectical endoxa nor to any dialectical discussion and explains this fact in terms of the close connection between historia and empeiria found at $G A 757 \mathrm{~b} 35-758 \mathrm{a} 3$. But a different historical explanation for this linguistic connection can be given in terms of the distinction in Plato's Phaedo (96b ff.) between the turn lo the logoi and the kind of inquiry pursued by the physiologoi. This is at suggest that the as Irwin's explanation (1987: 117) that Aristotle does not mon beliefs, shared by the discovered by historia thereby become comexpect that the results the many and the wise, because there is no reason to the many and the wise. (p. 118), Aristotle himself fails to explain the fact that, as Irwin concedes phainomena that precedes includes opinions and stories in the collection of that he does this only on the of his own phical inquiries. Irwin thinks record perceptual observation assumption that such opinions and stories weak; cf. Meteor. 350a16-18. The but his textual evidence for this claim is in showing that Aristotle relies on significantly that Irwin has not succeeded in empirical as distinct from diafificantly different sorts of appearances But perhaps Irwin has dialectical inquiries.

pursues two such different king grounds for his claim that Aristotle actually Within Aristotle's general account of a moiry under two different descriptions. to us towards things that are better of a movement from things better known 
between two different sorts of procedure. On the one hand, there is the progress from particulars to universals that comes under the general name of 'induction'; cf. APr. 68b35-37, APst. 71b33-72a5, Top. 105a16-19, 165a37. ${ }^{+2}$ Irwin (1987: 118) thinks that this description fits the kind of empirical inquiry that begins with perceptual phenomena and moves through experience to a general explanatory principle. On the other hand, Aristotle talks about a movement from the universal to particulars, since the undifferentiated whole is better known to perception, even though it is confused; cf. Physics I.1, 184a26-b14. He illustrates this point with the example of children who call all men 'father' and all women 'mother' because they have not yet made the necessary differentiations within these two classes. So the movement towards 'particulars' involves the articulation of some essential features that a thing must have in order for a name and definition to apply to it. Irwin (1987: 119) judges this description to correspond better with dialectical inquiry that begins from common beliefs because these correspond to a confused claim that needs to be clarified. ${ }^{43}$ Furthermore, it seems to fit the Topics (100a18 ff.) description of dialectical method which says that the first principles of the philosophical sciences can be examined by beginning with the common beliefs and by working through the puzzles. By contrast, he claims, the descriptions of empirical inquiry do not contain references to common beliefs and puzzles. Therefore, Irwin thinks it reasonable to conclude that the terminology of dialectic is prominent where the relevant appearances are common beliefs, whereas there is no suggestion by Aristotle that he is conducting a dialectical argument where the observational appearances are concerned. He also finds this conclusion to be supported by noticeable differences in the general character of empirical and dialectical treatises in the Corpus.

Although Irwin's proposed distinction deserves thorough scrutiny, I must here confine myself to discussing a few key texts which mix empirical and dialectical modes of inquiry, and which therefore tend to undermine his proposed distinction. Let me begin with Generation and Corruption, which Irwin (1988: 29) regards as being dialectical in character. In Book I, Ch. 2, Aristotle introduces questions about generation and corruption as the main subject-matter of his inquiry, even though he also intends to discuss other kinds of change like growth and alteration. Instead of beginning with perceptual phenomena, Aristotle starts with a review of the opinions of predecessors, even though he confesses that very few of them said anything worthwhile on his topic. For instance, he claims that Plato only dealt with the generation and corruption of the elements, whereas Democritus gave serious attention to all kinds of change. In contrast to the superficial explanations (e.g. that things grow by the accretion of like to like) offered by other thinkers, the atomists hypothesized that the atoms have different shapes $(\sigma \chi \eta \mu \alpha \tau \alpha)$ such that generation and corruption can be explained in terms of the aggregation and segregation of atoms, while alteration is accounted for by their arrangement and position. Aristotle explains their reasons for offering such an account as follows:

Since they thought that truth was in appearance and that the appearances were infinite and contrary to each other, they made the figures infinite. ${ }^{44}$

The report that the atomists believed truth to be in appearances seems to conflict with the report of Sextus Empiricus ( $A d v$. Math. vii, 135-6) that

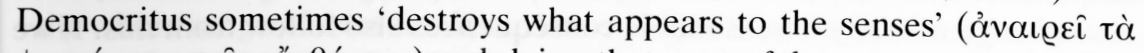

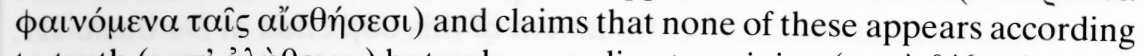
to truth ( $x \alpha \tau^{\prime} \alpha \dot{\alpha} \hat{\eta} \theta \varepsilon \iota \alpha \nu$ ) but only according to opinion ( $\left.x \alpha \tau \dot{\alpha} \delta \dot{\delta} \xi \alpha \nu\right)$; cf. fr. 9. Yet Aristotle reports elsewhere (Met. 1009b11-12) that Democritus held 'the appearance according to perception' ( $\left.\alpha \iota \theta_{\eta} \sigma \iota v\right)$ to be necessarily true, since he assumed knowledge and perception to be identical. While these conflicting reports are relevant to the above passage, they create a puzzle as to how it should be read.

The key to the puzzle, I think, is that Aristotle sees the method of the atomists as being akin to that of astronomers who posit certain intelligible entities in order to save the appearances which prompt and guide the search for truth. For instance, he says that they took the appearances to be infinite and so they posited an infinity of shapes for the atoms. The most obvious motivation for such an hypothesis is their effort to save perceptible phenomena. In fact, other reports by Sextus Empiricus ( $A d v$. Math. vii, 136 and 138 ) indicate that Democritus held his atomic theory to be confirmed by 'bastard' perception, even though it was reached through the more legitimate judgment of the intellect. Furthermore, like Anaxagoras, he seems to have held that phenomena provide us with a glimpse of what is unclear to ordinary sense perception. Yet I am not concerned here with Democritus but rather with what Aristotle's remarks tell us of his own methodological views on empirical inquiry. These remarks are embedded in a review of the opinions of predecessors about generation and corruption, which Aristotle gives as an essential preamble to his own inquiry:

So we must concentrate on these topics in our thinking; for they include a number of well-argued dilemmas. For if generation is aggregation many impossible consequences follow. But again there are compelling arguments on the other side, which is not easy to escape from, that it cannot be otherwise; and if generation is not aggregation either there is no such thing as generation at all or it is alteration - or
else we must try to escape this dilemma too, difficult though else we must try to escape this dilemma too, difficult though it is. ${ }^{45}$

According to Irwin's proposed distinction, this passage illustrates the sort of aporia, resulting from a conflict of common opinions that is part of a 
knowledge, although their being (Eival) is not the same. As usual, Aristotle begins his inquiry by gathering the relevant phenomena, some of which are things people like Euripides have said, whereas others are things that seem

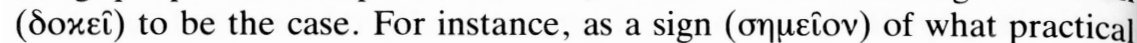
wisdom requires, he cites the fact that while young people can be clever at mathematics, it does not seem (oủ $\delta o x \varepsilon \hat{)}$ ) that they become practically wise; $1142 \mathrm{a} 11 \mathrm{ff}$. Whatever way one understands this piece of evidence, I think that Aristotle presents it not as a common opinion but rather as an empirical observation. This reading is supported by his subsequent logical and epistemological explanation that practical wisdom deals not only with universals but also with particulars, which become known through experience ( $\varepsilon \mu \pi \varepsilon \iota i \alpha)$. It is in this context that we should take Aristotle's observation that a young person lacks the sort of experience required for good judgment in practical affairs.

I think it is also significant that Aristotle assumes ethics and physics to be alike, when he considers the reasons why a boy can become a mathematician but not practically wise:

Surely it is because mathematical objects are reached through abstraction, whereas the origins in these other cases are reached from experience. Young people then [lacking experience] have no real conviction in these other sciences, but only say the words, whereas the nature of mathematical objects is clear to them. ${ }^{50}$

What makes physics and ethics similar in this context is that both sciences reach their appropriate first principles through experience ( $\dot{\varepsilon} \xi \xi \dot{\varepsilon} \mu \tau \varepsilon £(i \alpha \varsigma)$, whereas mathematics grasps its principles through abstraction ( $\delta$ '

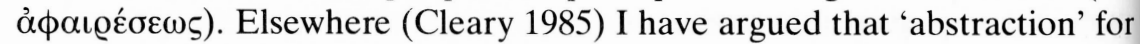
Aristotle is primarily a logical method of subtraction that enables the mathematician simply to posit his subject genus and to demonstrate that universal predicates belong to it. My argument is consistent with Aristotle's tendency to characterize the exclusively mathematical approach of the Pythagoreans and Platonists as a 'logical' type of inquiry, by contrast with the more 'physical' type of inquiry conducted by Democritus. But even on an epistemological interpretation, it would not be possible to line up ethics and physics on different sides of the logical/physical distinction with respect to their methods of inquiry. Just like astronomy, both sciences require exten sive acquaintance with the relevant sorts of phenomena before the appropri ate first principles are discovered. Contrary to Irwin, what this passage suggests is that for Aristotle both ethics and physics are empirical sciences with similar methods, despite the fact that they deal with quite different kinds of appearances. ${ }^{51}$

From this perspective, let me now examine the passage from $N E$ VII.1 which is usually exhibited as evidence that Aristotle had in mind a different method of inquiry for ethics. As part of his introduction to an inquiry about akrasia and related topics, he says the following:

As in the other cases we must set out the appearances, and first of all go through the puzzles. In this way we must prove the common beliefs about these ways of being affected - ideally, all the common beliefs, but if not all, then most of them, and the most important. For if the objections are solved, and the common beliefs are left, it will be an adequate proof. ${ }^{52}$

As Barnes (1980) points out, the method of endoxa outlined here seems to consist of three distinct steps: (1) laying out ( $\tau \iota \theta \varepsilon \dot{\varepsilon} \sim \iota)$ the appearances; (2)

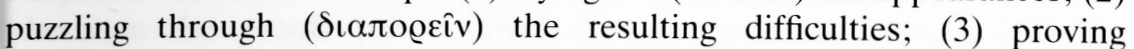

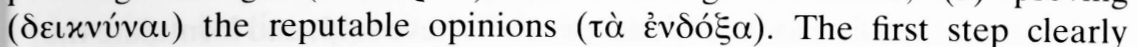
involves a review of the relevant phenomena which in this case are things said

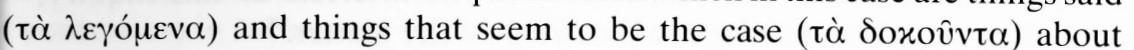
incontinence ( $E N 1145 \mathrm{~b} 20$ ). For instance, it seems ( nent person is one who abandons his rational calculation, whereas the continent person abides by his reasoning (1145b111-12). Now, while one might concede that this is a different sort of phenomenon from what one finds in physics or meteorology, it does not follow that they all involve different methods of inquiry. In fact, the first stage of setting out the phenomena in ethical inquiry corresponds to what Aristotle describes in the Prior Analytics as the initial stage of any empirical inquiry. Similarly, the last stage of proving the endoxa can be taken to correspond with the final step of 'saving the phenomena', in which one must show that the explanatory hypothesis is confirmed by the phenomena..$^{53}$

Thus Irwin's case rests heavily on his claim (1987: 127) that puzzles play a different role in dialectical inquiry than in empirical inquiry, especially with reference to the testing and confirmation of a theory. Even though he concedes that the presence of puzzles does not distinguish one type of inquiry from the other, he insists that puzzle-solving is not an essential condition for the adequacy of an empirical theory as it is for a dialectical solution. In his own words, Irwin finds no reason to think that Aristotle believed authoritative perceptual appearances to lose caste if they cannot be explained by some plausible empirical theory. By contrast, the existence of dialectical puzzles represents a challenge to the truth of appearances such that none of them can be treated as authoritative until the puzzles are resolved. If this could be documented as Aristotle's explicit view then the unitarian thesis might be undermined, but the best that Irwin has to offer is circumstantial evidence. For example, he finds it significant that Aristotle mentions puzzle-solving only in his description of an adequate dialectical theory and not for an empirical theory. The reason, Irwin thinks, is that a egitimate empirical inquiry may still leave puzzles unresolved for the lack of 
appropriate appearances, which may yet be gathered through further histo ria. Thus, for instance, Aristotle concedes that the phenomena of the heavens tend to be scarce and inaccessible, so that one must construc corrigible hypotheses from what is available. Irwin argues that no simila suggestion is made about dialectical inquiry because an exhaustive survey 0 its relevant appearances does not depend on empirical inquiry. ${ }^{54}$ Yet Irwi has given no convincing reason for denying that the collection of commo opinions is not a form of empirical inquiry for Aristotle.

Furthermore, contrary to what Irwin claims, we find Aristotle givin prominence to common opinions and puzzles in connection with som empirical inquiries. In De Caelo IV.1, for instance, he introduces his treatis on weight and lightness as follows:

We must then first look at whatever others have said, and formulate the questions which require settlement in the interests of this inquiry, before we go on to state our own view of the matter.

Although Aristotle gives no specific names, it is clear that he has in mind th opinions of predecessors such as Plato and Democritus, especially since $h$ proceeds to examine the theory of weight outlined in the Timaeus. Th purpose of such an examination is to review the difficulties ( which must be resolved by the explanation that Aristotle himself will p forward. Barnes (1980) thinks that this passage ascribes a purely meth odological function to the collection of endoxa, i.e. that it does not dete mine and circumscribe the area of legitimate inquiry. ${ }^{56}$ But it is difficult to se how a collection of the relevant phenomena can fail to clarify the subject matter in question. For instance, in the treatise on weight in De Caelo IV Aristotle emphasizes that all previous theories are inadequate in that the deal only with relative weight and fail to define or use absolute weight as a explanatory principle ( $308 \mathrm{a} 34 \mathrm{ff}$.). Although one is left with the gener impression that the review of difficulties serves only to prepare the way $f$ Aristotle's own account of absolute weight, yet one must not forget that th account will also have to explain the phenomena of relative weight. Hov ever, it is clear throughout the treatise on weight that sensory phenomer must be 'saved' in preference to common opinions; cf. 308b18, 309a26-

So there is an unanswered question about the methodological function the reviews of common opinions usually found at the beginning of Aristotle scientific treatises. Irwin thinks that resolving the associated puzzles unnecessary for an adequate empirical theory, whereas it is an essential pa of an adequate dialectical theory. But it seems to me that the review opinions plays an important logical role in Aristotle's empirical inquirie even if such opinions are not the crucial phenomena to be saved. In $\mathrm{De} C \mathrm{Ca}$ I.10, for instance, he introduces a treatise on the eternality of the world wi a review of opinions, which he justifies as follows:
Let us start with a review of the theories of other thinkers; for the proofs of a theory are difficulties for the contrary theory. Besides, those who have first heard the pleas of our adversaries will be more likely to credit the assertions we are going to make. We shall be less open to the charge of procuring judgement by default. To give a satisfactory decision as to the truth it is necessary to be rather an arbitrator than a party to the dispute. ${ }^{57}$

On the face of it, this passage seems to support the view that reviewing the common opinions is merely a preliminary task for Aristotle in an empirical inquiry but I think that closer scrutiny shows something else. First, he

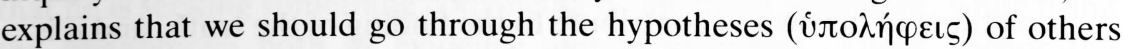

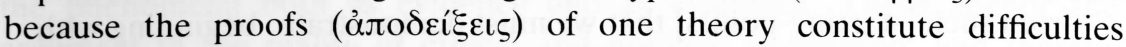

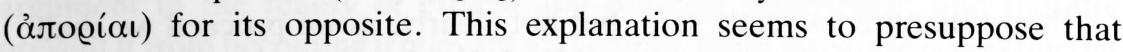
competing theories are related as logical contradictories (or at least as contraries) in such a way that the objections against one theory could serve as supporting evidence for another. If that is the case then the puzzles which arise from Aristotle's review of opinions can be used to confirm his own theory, especially when it resolves them in the final movement of the inquiry. The presupposition here is that one can give an exhaustive outline of logical possibilities which provides the framework, not only for the initial collection of opinions, but also for the subsequent empirical inquiry. In this light we can make sense of Aristotle's characteristic use of $\lambda$ o $\gamma \iota x \omega \varsigma$ inquiry as a preliminary to $\phi v \sigma \iota x \omega \varsigma$ inquiry.

In the latter part of the above passage, Aristotle justifies his procedure in the language of forensic oratory, which explains the epistemological (rather than logical) function of a review of common opinions. He claims that the subsequent arguments will inspire greater confidence if the arguments of the disputants have already been given a fair hearing. The reason for such confidence is that the successful theory will have survived in a fair competition rather than winning by default. Continuing the forensic metaphor, Aristotle concludes that the seeker after truth must be an arbitrator rather than a litigant, presumably since the latter is too intent on winning the argument. This reminds us of his remark that the Pythagoreans and Platonists, in adopting mathematical principles of explanation for physics, are like people engaged in argument who defend their position at the cost of the truth. By contrast, Aristotle adopts the posture of an arbitrator who seeks the truth somewhere between two competing sets of claims and arguments. According to this forensic model of inquiry, therefore, the review of common lawcourts, while the claims and counterclaims of plaintiffs in the a principle whe function of the inquirer is that of a good judge who finds principle is and resolve the dispute and to give each plaintiff his due. This natural sciences. 
This analogy is clearer in the Eudemian Ethics where, as Allan (1961) ha argued, there are some traces of a quasi-mathematical method in Aristotle's procedure, even though he pays close attention to the facts of moral experience. In discussing competing views of human happiness in relation to virtue and wisdom, Aristotle offers his methodological manifesto:

We must try, by argument, to reach a convincing conclusion on all these questions, using, as testimony and by way of example, what appears to be the case. For it would be best if everyone should turn out to agree with what we are going to say; if not that, that they should all agree in a way and will agree after a change of mind; for each man has something of his own to contribute to the finding of the truth, and it is from such [starting-points] that we must demonstrate: beginning with things that are correctly said, but not clearly, as we proceed we shall come to express them clearly, with what is more perspicuous at each stage superseding what is customarily expressed in a confused fashion. ${ }^{5 x}$

In order to grasp the significance of this passage, we must read it in the context of Aristotle's previous distinction between theoretical, productive, and practical sciences in terms of their goals. Since this distinction was made by way of response to the excessive intellectualism of Socrates in ethical matters, there can be no question of Aristotle's own method being based on a confusion between theory and praxis as the ultimate goal of ethical inquiry. So we must keep in mind what he says elsewhere about 'the fact' ( being adequate as a first principle in ethics, since that is sufficient as principle of action for a person with the right habits. In the above meth odological passage, however, Aristotle appears to be speaking at a higher philosophical level of reflection which emphasizes the truth of the conclusions more than their persuasiveness as principles of action. This is confirmed by the subsequent passage (1216b35 ff.) which distinguishes between a philosophical and a non-philosophical approach in every discipline. Aris totle insists that the politician should not disregard as irrelevant a philosophi cal inquiry about the cause ( fact. Such an inquiry is necessary for the politician if he is not to be taken in by those sophists who talk like philosophers about politics but who, in fact.

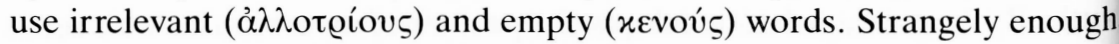
the politician is duped not through lack of experience in politics but through lack of education ( $\alpha \pi \alpha \iota \delta \varepsilon v \sigma i \alpha)$, which renders him unable to distinguish between arguments that are appropriate (oixcíovऽ) to the subject-matter

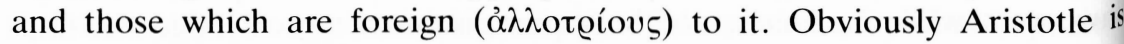
referring to the notorious success which rhetoricians enjoyed in the Athe nian democracy, even though they knew little about political matters. According to him, one way to guard against such charlatans is to test the

\section{PHAINOMENA IN ARISTOTLE'S METHODOLOGY}

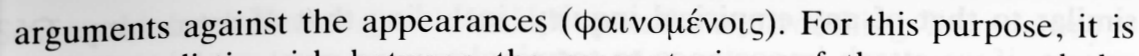
useful to distinguish between the account given of the cause and the conclusion drawn from it, since the conclusion may be true but not for the reason given, as Aristotle shows in his Analytics. The reference to the Analytics is very revealing because it shows that he has the demonstrative model in mind here, when he distinguishes between the account given of the principle and what is deduced from it.

Within such a framework, I suggest that the above methodological passage is primarily concerned with the way 'to' the first principles of ethical and political science. From this point of view, it makes sense for him to say that he is seeking something convincing by means of argument, while using the phenomena both as evidence and as examples. These anchor the argument in the reality of ethical and political experience, and thereby prevent it from becoming irrelevant and empty. Here Aristotle is seeking the right balance between $\lambda \sigma \gamma \iota x \omega \varsigma$ and $\phi v \sigma \iota \omega_{\varsigma} \varsigma$ types of inquiry, both of which are deemed necessary for a comprehensive treatment of the subject-matter. Furthermore, consensus omnium remains his ideal criterion of truth, though he is prepared to settle for qualified agreement as a result of some dialectical persuasion. Behind this ideal lies Aristotle's deep conviction about the human capacity for truth which is the real ground for the possibility of scientific inquiry. As he puts it himself, we begin from things that are true but unclear and proceed to principles that are both clear and true; so that we can use these as premises in constructing our demonstrations. Indeed, one may spy here an implicit parallel between the progress of an individual towards knowledge and the development of a whole field through a tradition of inquiry in which someone made the all-important start, though it was still unclear, while subsequent thinkers (like Aristotle) reached clear first principles and completed the science.

Finally, a brief look at a passage from the Eudemian Ethics which makes some methodological remarks that parallel those we have examined from the Nicomachean Ethics. The passage, which finds its context within a general discussion of friendship, goes as follows:

We must, then, find a method that will best explain the views held on these topics, and also put an end to difficulties and contradictions. And this will happen if the contrary views are seen to be held with some show of reason; such a view will be most in harmony with the phenomena; and both the contradictory statements will in the end stand, if what is said is true in one sense but untrue in another. ${ }^{59}$

From the methodological point of view, perhaps the most noteworthy thing

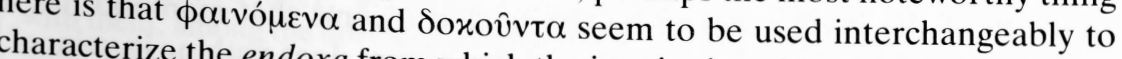
seems to suggest that Aristotle saw the method of ethical inquiry as being 
imilar to that of any empirical inquiry, including that of astronomy. Of course, if we attach importance to terminology, we must explain why the

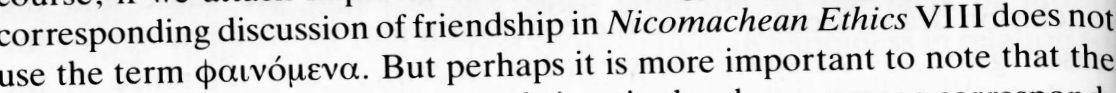
whole description of ethical method given in the above passage corresponds perfectly to the procedure of the treatise on action and passion in Generation and Corruption I.7. In both cases we begin with phenomena that seem to conflict and so give rise to puzzles, which must be solved by some explanatory principle that shows most of the phenomena to be well founded and hence, not really conflicting. Thus, in contrast to what Irwin claims, there is little convincing textual evidence that Aristotle saw the method of ethical inquiry as being different in kind from that of more empirical types of inquiry.

\section{Conclusion: The Cyclical Return of Truth}

From our modern perspective it is difficult to understand how Aristotle could have failed to see the difference between the methods of different types of inquiry, especially since he distinguishes them in terms of subject-
matter and even warns us against expecting the same kind of precision in ethical inquiry as one finds in mathematics. But for him the degree of precision to be sought in a science is decided by the complexity of its subjectmatter rather than by any difference in its method of inquiry. For instance astronomy is less exact than geometry, even though both use a mathematica method, because astronomy must deal with the additional physical aspects of the heavenly bodies. So the distinction between these two related sciences illustrates the difference between logical and physical modes of inquiry but not Irwin's distinction between dialectical and empirical kinds of inquiry.

Yet it would be legitimate for someone to object that I have not given any solid Aristotelian evidence for ruling out the possibility of the latter kind of distinction. Perhaps the best that one can do is to point towards some scattered hints that Aristotle held some views about the cyclical return of truth which would undercut Irwin's distinction between empirical and dialectical inquiry. For instance, his Politics combines historical research into the constitutions of Greek cities with dialectical reviews of common opinions about the best political order. In Aristotle's mind these represent merely two avenues to a single set of truths that have already been discovered and forgotten many times by previous generations; cf. Pol. 1264a1-4, $1329 \mathrm{~b} 25-30$. I have already noted that he often appeals to this myth of eternal return, as if he finds truth in it; cf. De Cael. 270b19 ff., Met. 1074b10 13, De Phil. Fr 8 (Ross), Protr. Fr 8 (Ross). The grounds for his confidence in the truth of the myth seem to be the related axioms that mankind has a natural inclination towards the truth and that nature does nothing in vain; $\mathrm{cf}$. Met. 980a21, 993a30-b4, EN 1143b6-9, EE 1212b26-36, Rhet. 1355a15-18.
So if no thinker before Aristotle had hit upon the truth of things in some way, his would involve a systematic frustration of the purposes of nature which he could hardly credit. Besides, his method of reviewing the common opinions s grounded on the assumption that previous thinkers had some grasp of the ruth, even if they were not entirely clear about it; cf. EE 1216b32-4, Pol. 1280a9. This means that he sees scientific problems and their possible olutions as being defined by the tradition of inquiry in each field, whether this be politics, physics or philosophy. Even with reference to the science of astronomy where both observations and theories remain uncertain, Aristoe seems confident that the Egyptians and the Babylonians have discovere the truth already and that human ingenuity will recover it.

\section{Boston College \& St Patrick's College, Maynooth}

\section{Notes}

This paper was completed in Spring 1993 during a period of research leave spent at Heidelberg University with financial support from the von Humboldt Foundation.

Since there is a scholarly dispute as to whether Aristotle has one or more than one method of inquiry, I do not wish to beg the question in this paper when I use the singular for the sake of convenience, while discussing the issue about the singularity or plurality of his methodology. Aristotle's term 'method' may itself imply a plurality of 'ways' because $\mu \varepsilon \dot{\theta} \theta 0 \delta$ s can refer to any discipline

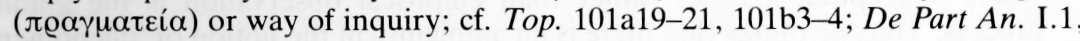
$639 \mathrm{a} 1$.

2 For Aristotle the goal of the practical sciences is action, and for this the fact (tò ö $\tau$ ) is sufficient as a first principle; whereas theoretical sciences require a

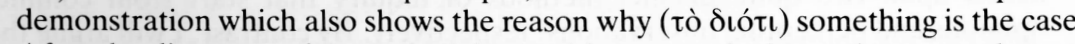
After the discovery of first principles in either type of science, however, the way 'from' the principles is mapped out in syllogistic form by Aristotle. Thus, for purposes of this paper, the crucial question is whether the way 'to' the principles has a common structure.

Mittelstrass (1962) claims that Eudoxus was responsible for coining the phrase

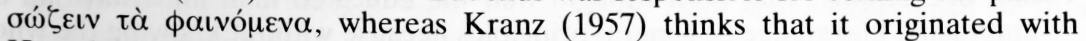
Heracleides Pontus. Skemp (1979) rightly points out that, whoever coined the phrase, its proper historical context is the planetary problem in ancient astronomy.

Among the Presocratic natural philosophers, the term фaıvó $\mu \varepsilon v \alpha$ had a much broader reference to all natural appearances, which are thought to provide a glimpse of a hidden reality; e.g. Democritus (DK 55A111) and Anaxagoras

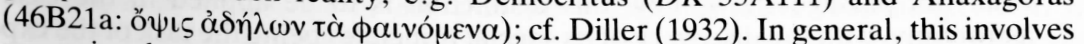
reasoning by analogy from the visible to the invisible, by contrast with the hypothetical method used in the Pythagorean and Platonic tradition.

Most of what survives from Eudoxus' Phainomena is in a verse form made by Aratus; e.g. Fr 110-11: 'When the Fishes [Pisces] rise, one can see rising along with them, among the northern constellations, the rest of Andromeda, the righthand side of Perseus, the Triangle which is above the Ram; and among the southern constellations the head of the southern Fish. One can see setting at the 
same time among the southern constellations the Altar and the rest of Hydra among the northern constellations, one is setting.

6 Fr 11: 'There is a certain star which always remains in the same spot, and this st is the pole of the universe.' This conflicts with the more accurate report of Pytheas of Marseilles that there is no star at the pole but an empty space surrounded b three stars roughly forming three angles of a square. In order to explain such conflict, Lasserre (1964: 130) suggests that Eudoxus imagined a star at the pol because he had a preconceived idea that the pivot of the sky must be marked in this way.

7 Met. 1073b3-8: translation by Apostle (1966).

8 Cf. Phy. 196a33; Met. 1026a18, 1074a30; EN 1141b2-3.

9 Throughout this paper I use the term 'empirical' not in the modern positivis sense but in the ancient sense of something that involves experience ( $\varepsilon \mu \tau \varepsilon\llcorner\varrho \iota \alpha)$ Similarly, Irwin appeals to the Aristotelian account of how one gains experience as a result of sense perception, but he takes this to be quite different from ar inquiry that begins with common opinions. Yet I see no good reason to attribut this distinction to Aristotle, and hence I take experience to cover all types processes which yield appropriate general principles in different kinds of inquir e.g. habituation in ethics or dialectical practice in philosophy.

10 Met. 1073b10-17: translation by Apostle (1966).

11 Ernest Kapp (1942) has shown convincingly that the search for appropriate premises to construct a syllogism is best understood in terms of a dialectic situation in which one already knows the conclusion (e.g. the fact that the planet do not twinkle) but not the reason why (i.e. that they are near).

12 Prior Analytics I. 30, 46a18-26: translation by Jenkinson in Barnes (1984).

13 By contrast, Owen (1961) takes this empirical method to be associated exclusive with inquiry in natural science (iotogí $\alpha$ ) because he does not find it in the Physi where conceptual analysis rather than empirical observation is the guidin process. Thus he thinks that there is an ambiguity in the notion of "phenomen which corresponds roughly with the distinction between endoxa and perceptu phenomena. Irwin rejects Owen's thesis about two senses of phenomena, y insists upon two quite distinct methods of inquiry that start from commo opinions and perceptual observations, respectively. By contrast, I will argue th there is a single common method, but that the meaning of 'phenomena' is alwa relative to the subject matter; e.g. physical vs. moral phenomena.

14 De Part. An. I.1, 639b7-11: translation by D. M. Balme (1972).

15 Balme (1972: 70) thinks that Aristotle is here taking his usual stance against Pla and Speusippus, who both thought that the educated man must have an a embracing knowledge of general principles because without knowing the who one cannot know the part. By contrast, Aristotle holds that each science propos its own axioms and so can be known independently of other sciences, with t result that its general principles and procedures are also independent. Later I w argue that such opposition to Platonism is encapsulated in his general distinctio between inquiry conducted $\lambda \circ \gamma \iota x \omega \hat{s}$ and $\phi v \sigma \iota x \omega \hat{s}$ or $\alpha \dot{v} \alpha \lambda v \tau \iota x \omega \hat{s}$. The Pri Analytics passage shows how this distinction is to be applied in the case astronomy, with the discovery of its special principles being the task of the expe while the generalist is able to judge the logical correctness of his procedure.

16 David Balme (1972: 72-3) suggests that Aristotle's reason for this is that he thin the generic attributes may reveal the causes of specific attributes. But I find mo plausible Kullmann's (1974) suggestion that the distinction between the colle tion of phenomena and the search for causes corresponds closely to th

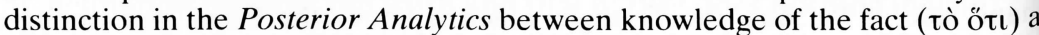

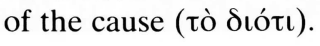

17 Meteor. 339b20-7: translation by Webster in Barnes (1984).

18 Meteor. 344a5-8: translation by Webster in Barnes (1984). Cynthia Freeland (1990) finds this passage to be so contrary to Aristotle's explanatory realism that she is inclined to treat it as an interpolation, but I do not think one can avoid its implications so easily.

19 Leszl (1981: 319) also notes that, even in procedures for explaining empirical data, when these data are given linguistic expression they are held by Aristotle to 'accord' with each other and with hypotheses in the same way as in a strictly dialectical procedure.

20 J. B. Skemp (1979) also finds in Aristotle a similar tendency to subordinate empirical evidence to theory, especially with regard to the existence of a fifth element and of an unmoved mover. For Skemp the outstanding example of this tendency occurs in De Caelo II.7 where Aristotle introduces the analogy of missiles igniting through friction to explain how stars composed of ether can give light and how the sun gives us heat by virtue of the lowest sphere rubbing against the air at a great speed.

21 This correlation is called a $\varepsilon \varepsilon x \mu \eta \dot{\jmath}$ for Aristotle that there is a necessary causal relationship between the appearance of many comets and the subsequent wind and drought. His concept of a $\tau \varepsilon \varkappa \mu \eta \dot{\varrho} \varrho\llcorner\vee v$ is that of a necessary sign from which a syllogism can be constructed, and his favourite example is that a woman with milk must have given birth; cf. Rhet. I.2, $1357 \mathrm{~b}$.

22 Since this event is usually dated around 467 BC Aristotle must be relying on eyewitness or hearsay reports that were well over 100 years old when he proposed his explanation.

23 Irwin (1987: 115) concedes that Aristotle has to rely on common beliefs, tradition, and other non-perceptual appearances, when direct observation is impossible. Yet he insists that Aristotle shows himself to be well aware of the difference between perceptual and non-perceptual appearances, though convincing textual evidence for this awareness is scarce. Indeed, Irwin (p. 116) himself admits that the distinction between perceptual appearances and common beliefs may not always be very sharp in Aristotle's practice; cf. GA 778b7-10.

24 Cael. 270b1-6: translation by Stocks in Barnes (1984)

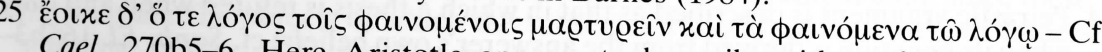
Cael. 270b5-6. Here Aristotle appears to be guilty either of the fallacy of affirming the consequent or of arguing in a circle. But I think that he can be cleared of such charges when we see that, whereas the principles that explain the phenomena are accepted hypothetically, the phenomena are held to be trustworthy in themselves because they are supplied from sense experience or from reputable opinions.

26 Walter Leszl (1981: 317) makes a useful distinction between broader and narrower senses of 'hypothesis' in Aristotle. He thinks the narrower sense is agreed assumptions athematics and dialectic, which both seem to be based on 1005a11-13, dialectical debate; cf. APr. $49 \mathrm{~b} 33$ ff., APst. I.10, Met principle of knowledge on contrast, the wider sense means any kind of firs 81b14-15, Met. 1013a14 or any premise of demonstrative reasoning; cf. APst. demonstrative premia14-16, 1013b2021. Aristotle sometimes stresses that even sense) because they ased on empirical evidence are hypotheses (in the broad evidence and they are still consciously postulated as a result of assenting to the tions of empirical dosing an appropriate formulation. Furthermore, in explana( $v \mu \phi \omega v \varepsilon i ̂ v)$ comparable their relation to hypotheses is one of 'accord'

27 Even though the Greek text the situation in dialectic and mathematics. evidence and comment contains an implicit contrast between observational opinion, it is noteworthy that both kinds of evidence are 
held to be consistent with Aristotle's approach to empirical cosmology. See Oehler (1961) on the use of consensus omnium as a criterion of truth in ancient philosophy.

28 Such an etymology is given also in Plato's Cratylus (410b), so perhaps it had some currency.

29 Irwin (1987: 120) follows Owen in claiming that aporiae in empirical inquiries wil] tend to be about empirical facts, whereas they are logical or philosophical puzzles in the case of dialectical inquiries. In the first case, the source of puzzles is empirical ignorance about facts or their explanation, whereas, in the second case, the presence of persuasive arguments on both sides of a question leads to dialectical puzzles.

30 De Caelo II. 13, 293a21-30: translation by J. L. Stocks in Barnes (1984).

31 De Caelo IV.1, 308a21-2, says that the circumference is prior by nature ( $\tau \hat{r}$

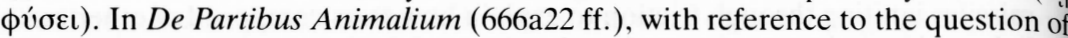
whether the heart is the source and receptacle for blood, Aristotle entertains the logical $(\lambda \mathrm{o} \gamma \iota \varkappa \hat{\omega} \varsigma)$ argument that the centre is best suited to being a source, since it is equally within reach of every part. In his discussion this sort of inference is contrasted with the kind of evidence derived from the senses; e.g. that the heart is the first thing to be set in motion in the embryos of chickens is evident from the 'experiment' of opening one egg per day from a clutch of hatching eggs.

32 Solmsen (1960: 260) thinks that the departmentalization of the sciences reveals the 'forma mentis' of Aristotle, as distinct from Plato. But I would suggest that perhaps one can understand how he arrived at this position through a criticism of the universalism in Plato's approach to knowledge; i.e. the assumption that a scientist must have an all-embracing knowledge of general principles or, as Speusippus held, that without knowing the whole one cannot know the part. In De Philosophia there is some evidence of a reaction against the 'logical' $(\lambda \mathrm{o} \gamma \iota \hat{\omega} \varsigma)$ derivation of visible reality from higher principles; cf. Aristoxenus, Harm. II. 30-1. See also De Partibus Animalium I.1 where Aristotle distinguishes between the generally educated person and the specialist in some subject.

33 De Caelo II.13, 294a6-13: translation by Stocks in Barnes (1984).

34 Peirastic argument is described as that in which a thesis is refuted when and onl when its negation is derived from the answerer's own beliefs; cf. Soph. El. 165b35. This is the kind of argument which is amply illustrated by Plato's Socratic dialogues and so it was central to Aristotle's concept of dialectic as a kind of mental gymnastics that is useful for ordinary encounters; cf. Top. 101a25 ff. It may also be described as 'logical' $(\lambda \circ \gamma(x \omega))$, by contrast with 'physical'

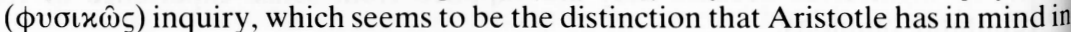
this passage; cf. Soph. El. $2 \& 11$

35 This passage is consistently cited (by Irwin and others) as evidence that Aristotie had two entirely different criteria of truth for dialectical and empirical inquiry. But here and in other places Aristotle appeals to both criteria in conjunction during an empirical inquiry, as if they were correlative general and specific criteria; cf. De Part An. $666 \mathrm{a} 22$ ff. Such passages suggest that the $\lambda \sigma \gamma \iota x \omega \tilde{\varsigma} / \phi v \sigma \iota x \hat{\omega} \varsigma$ distinction might be more appropriate for differentiating these two types of argument which can be given within any kind of inquiry.

36 See De Caelo $306 a 26 \mathrm{ff}$. where Aristotle says that the Platonists are so eager t

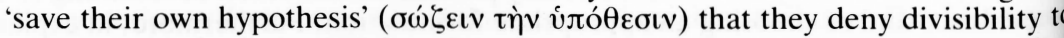
some sensible bodies, even though mathematicians grant it to intelligible bodies. The point of his remark seems to be that their mistaken principles prevent them from 'saving the phenomena' for both the physical and mathematical realms. 37 De Caelo III.7, 306a10-18: translation by Stocks in Barnes (1984).
In De Partibus Animalium I.1, Aristotle distinguishes between natural ( $\phi v \sigma \iota x \eta ́)$ and theoretical $\left(\theta \varepsilon \omega \varrho \eta \tau \iota \eta^{\prime}\right)$ science in terms of the mode of necessity involved in demonstrations for each kind of science. Since proofs in the former begin from

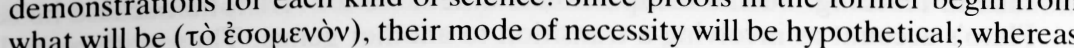

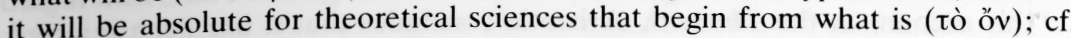
640 1 is noteworthy that, despite their different modes of necessity, demonstrations in both types of inquiry have the logical form of hypothetico-deductive argumentation. This suggests that Aristotle wants to retain the same general form of proof even where there are wide differences in necessity and accuracy.

Topics VI.4 may be relevant to this issue, since it claims that what is clear to perception is more familiar to us rather than more familiar absolutely; cf. 141b34 ff. But Aristotle does allow that what is intelligible absolutely may coincide with what is intelligible to those in a sound intellectual condition, just as what is healthy absolutely is identical with what is healthy for those who are physically sound. I think this is similar to the ideal of the phronimos in ethics and politics, while the fair arbitrator is the corresponding ideal in dialectical inquiry; cf. Met. III.1, 995b2-4, EN 1113a22-5 \& 1176b24-5.

Robert Bolton (1987) has also argued that the ad hominem element in dialectical argument excludes the possibility of its using new observational results, even those of an individual expert, because these data do not count as endoxa as defined at Topics 100b21-3. But Aristotle's definition leaves open the possibility that the view of a single expert might be counted as an endoxon; e.g. the view of Socrates on akrasia in EN VII.1. Enrico Berti (ms.) has argued for such a special use of endoxon.

J. Donald Monan (1968: 97) has shown that Aristotle's appeal to language in the Ethics involves calling upon the moral experience of language users who attribute praise or blame to certain actions.

But Kurt von Fritz (1964) has shown that induction in Aristotle has a wider meaning than that found in modern logic, since he uses the term for the process of bringing a particular under a universal in a dialectical situation. Irwin seems to assume that the narrow modern concept of induction also holds for Aristotle.

By contrast, Bolton (1987: 127n18) reads Physics I.1 as arguing that the data from which analysis starts in any physical inquiry must be perceptual data, since these fix what are the objects of which the subsequent inquiry gives a deeper understanding. In spite of the problematic nature of the whole passage, he thinks it is at least clear that what is more familiar to us is general information about the subject which we acquire by perception; cf. Phy. 184a24-5. With reference to this passage, Turnbull (1976) talks about 'sense universals' which are sufficiently complex to contain and confuse constituent elements; i.e. the principles or causes that are specific to the articulated species within a genus.

Gen. \& Corr. I. 2, 315b9-11: translation by Williams (1982).

Gen. \& Corr. I. 2, 315b18-24: translation by Williams (1982).

Gen. \& Corr. I. 2, 316a5-14: translation by Williams (1982).

in Physics III.5, Aristotle distinguishes between a more universal ( $\varkappa \alpha \theta$ ó $\lambda$ ov) inquiry about the existence of the infinite in intelligible objects like mathematicals and a more specific physical inquiry about sensible objects. Within this physically forward, it would $\varsigma)$. From the logical considerations that Aristotle brings forward, it would seem that the first approach involves drawing out the implicathe second follow from definitions of body and number, for instance. By contrast, e.g. that it would involves more physical arguments against an infinite body; suggests, however, overpower and destroy any finite body (204b10 ff). This passage rather than to a more general (dialectical) inquiry. 
48 In De Caelo I.10, Aristotle rejects a defence of Plato's 'generation' of an etern universe which compares it with the diagrams drawn by mathematicians for th sake of teaching. Such a comparison is untenable for Aristotle because he see Plato's account as involving a transition to another genus. Thus, with regard this account in the Timaeus, Aristotle concludes that it has been rejected 'physical' ( $\phi v \sigma \iota x \omega \varsigma)$ grounds, but he also refers to the possibility of a 'genera ( $x \alpha \theta$ ó $\lambda$ ov) discussion of the issue; cf. Met. 987b31-3, 1069a27-8, 1078b23 1087b18-21.

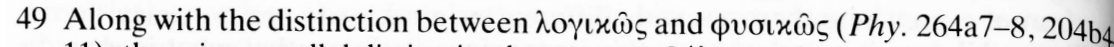
11), there is a parallel distinction between $x \alpha \theta$ ó $\lambda$ ov and $\phi v \sigma \iota x \hat{\text { s }}$ (Cael. $280 \mathrm{a} 32$ 3) which strongly suggests the historical difference between a Platonic type inquiry and the more concrete inquiry of the natural philosophers; cf. $D e A n$. I. 403a1-2, De Gen. An. II. 8, 747b27-30.

50 Nicomachean Ethics VI. 8, 1142a18-20: translation by Irwin (1985).

51 According to Aristotle (EN I.4, 1095b5-9) moral habituation provides the righ sort of experience for making 'the that' ( $\tau$ ò ö $\tau$ ) as a first principle obvious to th

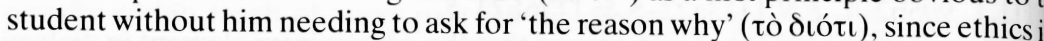
practical discipline whose goal is action rather than knowledge.

52 Nicomachean Ethics VII.1, 1145b2-8: translation by Irwin (1985).

53 At Nicomachean Ethics I.8 (1098b9 ff.) Aristotle outlines his proposed metho inquiry in ethics as follows: One must examine a first principle not only from th

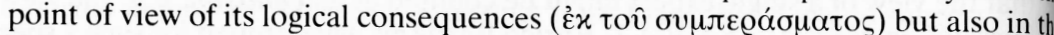
light of current opinions ( $\dot{\varepsilon} x \tau \hat{\omega} v \lambda \varepsilon \gamma o \mu \varepsilon \dot{\varepsilon} v \omega v$ ) because, if the principle is true,

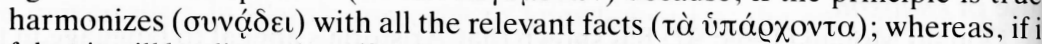
false, it will be discordant ( $\delta \iota \alpha \phi \omega v \varepsilon \hat{\imath})$ with them. The metaphors of harmony an disharmony here are reminiscent of Plato's description of the method of hypott esis in the Phaedo, which confined itself to internal logical consistency.

54 But in several dialectical contexts Aristotle does suggest that his hypotheses m be corrigible, especially when he sets the modest goal of doing no worse than $h$ predecessors; cf. Metaphysics III. 1 and De Anima I. 1.

55 De Caelo IV. 1, 308a4-8: translation by Stocks in Barnes (1984).

56 Enrico Berti (ms.) has argued that endoxa are the authoritative phenome which must be 'saved' by a dialectical inquiry, and that they are not to identified with the common beliefs which generate the puzzles. Yet there is litt textual evidence for such a distinction in Aristotle, except perhaps the significa absence of the term endoxon in connection with the initial gathering of legome which generate the puzzles in a dialectical inquiry. Thus, in Topics I.1, wh Aristotle says that dialectical syllogisms are made from endoxa, he is alrea talking about the way 'from' and not 'to' principles in any dialectical inquiry. T leaves open the possibility that common opinions (doxa) may provide the ini starting-point as things more familiar to us, rather than more familiar absolute

57 De Caelo I. 10, 279b6-13: translation by Stocks in Barnes (1984)

58 Eudemian Ethics I.6, 1216b26-35: translation by Woods (1982).

59 Eudemian Ethics VII. 2, 1235b13-18: translation by Solomon in Barnes (198

\section{Bibliography}

Allan, D. J. (1961) 'Quasi-Mathematical Method in the Eudemian Ethics', pp. 303-18 in S. Mansion (ed.) Aristote et les problèmes de méthode, Louvain: Publications Universitaires.

Anton, J. (ed.) (1980) Science and the Sciences in Plato, New York: Eidos.

Apostle, H. G. (1966) Aristotle's Metaphysics, Bloomington, IN: Indiana University Press.

Aubenque, P. (1961) 'Sur la notion aristotélicienne d'aporie', pp. 3-19 in S. Mansion (ed.) Aristote et les problèmes de Méthode, Louvain: Publications Universitaires. Aubenque, P. (ed.), (1979) Études sur la Métaphysique d'Aristote, Paris: Vrin

Balme, D. M. (1972) Aristotle's De Partibus Animalium I, Oxford: Clarendon Press.

Barnes, J. (1980) 'Aristotle and the Method of Ethics', Revue Internationale de Philosophie 133-4: 490-511.

Barnes, J. (ed.) (1984) The Complete Works of Aristotle, 2 vols, Princeton, NJ: Princeton University Press.

Berti, E. (1981) (ed.) Aristotle on Science. The Posterior Analytics, Padua: Antenore.

Berti, E. (unpublished paper), 'Is there a Development in Aristotle's Conception of Dialectic?'

Bolton, R. (1987) 'Definition and Scientific Method in Aristotle's Posterior Analytic and Generation of Animals', pp. 120-66 in A. Gotthelf and J. G. Lennox (eds) Philosophical Issues in Aristotle's Biology, Cambridge: Cambridge University Press.

Bolton, R. (1990) 'The Epistemological Basis of Aristotelian Dialectic', pp. 185-236 in P. Pellegrin and D. Devereux (eds) Biologie, logique et métaphysique chez Aristote, Paris: CRNS

Burnyeat, M. (1981) 'Aristotle on Understanding Knowledge', pp. 97-139 in E. Berti (ed.) Aristotle on Science, Padua: Antenore.

213 213-40 in A. Graeser (ed.) Mathematics and Metaphysics in Aristotle, Bern \&
Stuttgart: Haupt. XXX: 13-45. (1985) 'On the Terminology of "Abstraction” in Aristotle', Phronesis

The Philos. (1988) Review of The Fragility of Goodness by Martha Nussbaum in The Philosophical Review 97: 543-64. University Press.
Unicksty Greek Astronomy to Aristotle, Ithaca, NY: Cornell

Duhem,

Phenomena, Chicago: ta Phainomena, Paris: Vrin (tr. 1969. To Save the üring, I. (1961) 'A ristotle's

Aristote et les problèmes de method in Biology', pp. 213-21 in S. Mansion (ed.)

Evans, J. D. G. (1977) Aristotle's Cóth, Louvain: Publications Universitaires.

Press.

orology'. (1990) 'Scientific Explanation and Empirical Data in Aristotle's Metemétapy', pp. 286-320 in P. Pellegrin and D. Devereux (eds) Biologie, logique et métaphysique chez Aristote, Paris: CNRS.

Irwin, T. H. (1985) Aristotle in Aristotle, Oxford: Clarendon Press.

Irwin, T.H. (1987) 'Ways to First Pristoan Ethics, Indianapolis: Hackett.

Philosophical Topics XV: $109-34$.

Irwin, T. H. (1988) Aristotle's First Pri 
Kapp, E. (1942) Greek Foundations of Traditional Logic, New York: Colum University Press.

Klein, S. (1988) 'An Analysis and Defense of Aristotle's Method in Nicomache Ethics I \& X', Ancient Philosophy 8: 63-72.

Kranz, W. (1957) 'Zwei kosmologische Fragen', Rheinisches Museum für Philolog Band 100, pp. $114 \mathrm{ff}$.

Kullmann, W. (1974) Wissenschaft und Methode, Berlin: De Gruyter.

Lasserre, F. (1964) The Birth of Mathematics in the Age of Plato (trans. Mortimer), New York: American Research Council.

Leszl, W. (1981) 'Mathematics, Axiomatization and the Hypotheses', pp. 271-328 E. Berti (ed.) Aristotle on Science, Padua: Antenore.

Lloyd, G. E. R. (1978) 'Saving the Appearances', Classical Quarterly 28: 202-2?

Mansion, S. (1955) 'Les apories de la metaphysique aristotélicienne', pp. 141-79i Autour d'Aristote. Louvain: Publications Universitaires.

Mansion, S. (1961) (ed.) Aristote et les problèmes de méthode, Louvain: Publication Universitaires.

Mittelstrass, J. (1962) Die Rettung der Phänomene, Berlin: De Gruyter.

Monan, J. D. (1968) Moral Knowledge and its Methodology in Aristotle, Oxfor Oxford University Press.

Mourelatos, A. P. D. (1980) 'Plato's "Real Astronomy": Republic VII. 527D-531D pp. 33-73 in J. Anton (ed.) Science and the Sciences in Plato, New York: Eido Neugebauer, O. (1952) The Exact Sciences in Antiquity, Providence: Brown Uni Press.

Nussbaum, M. C. (1982) 'Saving Aristotle's Appearances', pp. 267-93 in Schofield and M. Nussbaum (eds) Language and Logos, Cambridge: Cambrid University Press.

Nussbaum, M.C. (1986) The Fragility of Goodness, Cambridge: Cambridge Univt sity Press.

Oehler, K. (1961) 'Der Consensus omnium als Kriterium der Wahrheit in d antiken Philosophie und der Patristik', Antike und Abendland X: 103-29.

Owen, G. E. L. (1961) 'Tithenai ta phainomena', pp. 83-103 in S. Mansion (6 Aristote et les problèmes de méthode, Louvain: Publications Universitaries.

Pellegrin, P. and Devereux, D. (1990) (eds) Biologie, logique et métaphysique ch. Aristote, Paris: CNRS

Schiaparelli, G. V. (1877) Le sfere omocentriche di Eudosso, di Callippo e Aristotele. Memorie del reale instituto Lombardo di scienze e lettere, Classe scienze matematiche e naturali, vol. XIII (Milano): 117-79.

Skemp, J. B. (1979) 'The Activity of Immobility', pp. 229-41, in P. Aubenque (ed Études sur la Métaphysique d'Aristote, Paris: Vrin.

Solmsen, F. (1960) Aristotle's System of the Physical World, Ithaca, NY: Corn University Press

Turnbull, R. G. (1976) 'Physics I: Sense Universals, Principles, Multiplicity a Motion', in Machamer and R. G. Turnbull (eds) Motion and Time: Space Matter, Ohio: Ohio State University Press.

Verdenius, W. J. (1960) 'Traditional and Personal Elements in Aristotle's Religio Phronesis V: 56-70.

Vlastos, G. (1980) 'The Role of Observation in Plato's Conception of Astronom pp. 1-31 in J. Anton (ed.) Science and the Sciences in Plato, New York: Eidos Vlastos, G. (1988) 'Elenchus and Mathematics', American Journal of Philology 1 $362-96$

Von Fritz, K. (1964) Die દ̇л $\alpha \gamma \omega \gamma \eta \dot{~ b e i ~ A r i s t o t e l e s, ~ M u ̈ n c h e n: ~ B a y e r i s c h e n ~ A k a d e n ~}$ der Wissenschaften.

Wardy, R. B. B. (1988) 'Eleatic Pluralism', Archiv für Geschichte der Philosophie $125-46$.
Wians, W. (1992) 'Saving Aristotle from Nussbaum's Phainomena', pp. 133-49 in J. Anton and A. Preus, Aristotle's Ontology: Essays in Ancient Greek Philosophy, vol. 5, Albany, NY: SUNY Press.

Williams, C. J. F. (1982) Aristotle's De Generatione et Corruptione, Oxford: Clarendon Press.

Woods, M. (1982) Aristotle's Eudemian Ethics, Books I, II \& VII, Oxford: Clarendon Press.

Wright, L. (1973) 'The Astronomy of Eudoxus: Geometry or Physics?', Studies in History and Philosophy of Science 4: 65-72. 